\title{
A fifteen-year overview of increasing tramadol utilisation and associated mortality and the impact of tramadol classification in the United Kingdom
}

\begin{tabular}{|c|c|}
\hline Journal: & Pharmacoepidemiology and Drug Safety \\
\hline Manuscript ID & PDS-17-0036.R1 \\
\hline Wiley - Manuscript type: & Original Report \\
\hline Date Submitted by the Author: & $n / a$ \\
\hline Complete List of Authors: & $\begin{array}{l}\text { Chen, Teng-Chou; University of Nottingham School of Pharmacy, Division } \\
\text { of Pharmacy Practice and Policy } \\
\text { Chen, Li-Chia; Manchester Academic Health Science Centre, University of } \\
\text { Manchester, Faculty of Biology, Medicine and Health, School of Health } \\
\text { Sciences, Division of Pharmacy and Optometry } \\
\text { Knaggs, Roger; University of Nottingham School of Pharmacy, Division of } \\
\text { Pharmacy Practice and Policy; Nottingham University Hospitals National } \\
\text { Health Service Trust, Pain Management Service and Pharmacy Department }\end{array}$ \\
\hline Keywords: & $\begin{array}{l}\text { tramadol classification, drug utilisation, interrupted time series analysis, } \\
\text { tramadol-related mortality }\end{array}$ \\
\hline Abstract: & $\begin{array}{l}\text { Purpose } \\
\text { This study aimed to develop hypotheses to explain the increasing tramadol } \\
\text { utilisation, evaluate the impact of tramadol classification and explore the } \\
\text { trend between tramadol utilisation and related deaths in the United } \\
\text { Kingdom. } \\
\text { Methods } \\
\text { This cross-sectional study used individual patient data, the Clinical Practice } \\
\text { Research Datalink from } 1993 \text { to } 2015 \text {, to calculate monthly Defined Daily } \\
\text { Dose (DDD)/1000 registrants, monthly prevalence and incidence of } \\
\text { tramadol users, annual supply days and mean daily dose of tramadol. } \\
\text { Aggregated-level national statistics and prescribing reimbursement data } \\
\text { from } 2004 \text { to } 2015 \text { were also used to quantify annual and monthly } \\
\text { tramadol DDD/1000 inhabitants and rate of tramadol-related deaths in } \\
\text { England and Wales. Interrupted time-series analysis was used to evaluate } \\
\text { the impact of tramadol classification in June } 2014 \text {. } \\
\text { Results } \\
\text { Prevalence of tramadol users increased from } 23 \text { to } 97.6 / 10000 \text { registrants } \\
\text { from } 2000 \text { to } 2015 \text {. Both annual dose and annual supply days of existing } \\
\text { tramadol users were higher than new users. Level and trend of monthly } \\
\text { utilisation ( } \beta 2:-12.9, \beta 3:-1.6) \text { and prevalence of tramadol users ( } \beta 2:- \\
6.4, \beta 3:-0.37) \text { significantly reduced after classification. Both annual } \\
\text { tramadol utilisation and rate of tramadol-related deaths increased before } \\
\text { tramadol classification, and decreased thereafter. }\end{array}$ \\
\hline
\end{tabular}




\section{Conclusions}

Increasing tramadol utilisation was influenced by the increase in prevalence and incidence of tramadol users, mean daily dose and day of supply. Prevalence of tramadol users, tramadol utilisation and reported deaths declined after tramadol classification. Future studies need to evaluate the influencing factors to ensure the safety of long-term tramadol use.

\section{SCHOLARONE ${ }^{m}$ \\ Manuscripts}


1 Title: A fifteen-year overview of increasing tramadol utilisation and associated

2 mortality and the impact of tramadol classification in the United Kingdom

3 Running head: Tramadol utilisation and related mortality

4 Names of authors: Teng-Chou Chen ${ }^{1}$, Li-Chia Chen ${ }^{2}$, Roger David Knaggs ${ }^{1,3}$

5 Names of the institutions:

6 1. Division of Pharmacy Practice and Policy, School of Pharmacy, University of $7 \quad$ Nottingham, Nottingham, United Kingdom

8 2. Division of Pharmacy and Optometry, School of Health Sciences, Faculty of 9 Biology, Medicine and Health, University of Manchester, Manchester Academic 10 Health Science Centre, Manchester, United Kingdom

11 3. Pain Management Service and Pharmacy Department, Nottingham University 12 Hospitals National Health Service Trust, Queen's Medical Centre Campus, 13 Nottingham, United Kingdom

14 Name of corresponding author: Roger David Knaggs

15 Address: East Drive, University Park, Nottingham, NG7 2RD, United Kingdom

16 Telephone: $+44(0) 1158466382$

17 Fax: $+44(0) 1158466249$

18 Email address: roger.knaggs@nottingham.ac.uk

19 Keywords: tramadol classification, drug utilisation, interrupted time series analysis, 
20 tramadol-related mortality

\section{Key points:}

22 1. The marked increase of tramadol utilisation in the UK primary care setting from

232000 to 2015 was influenced most by increasing prevalence, mean daily dose and

24 supply days for existing tramadol users.

25 2. The level and trend of monthly prevalence of tramadol users and tramadol

26 utilisation reduced after the classification of tramadol in June 2014.

27 3. From 2004 to 2013 , the annual tramadol utilisation doubled and coincidently the

28 number of tramadol-related deaths increased almost six times in England and

$29 \quad$ Wales, but their trends declined in 2014 and 2015.

30 Name(s) of any sponsor: University of Nottingham

31 Conflict of Interest statement: The authors have no conflict of interest to declare.

32 Word count: main text: 2999 words; abstract: 243 words

33 Prior postings and presentations: This paper has not been published previously

34 and is not under consideration elsewhere. 


\section{Abstract \\ 36 Purpose}

37 This study aimed to develop hypotheses to explain the increasing tramadol utilisation,

38 evaluate the impact of tramadol classification and explore the trend between tramadol

39 utilisation and related deaths in the United Kingdom.

\section{Methods}

41 This cross-sectional study used individual patient data, the Clinical Practice Research

42 Datalink from 1993 to 2015, to calculate monthly Defined Daily Dose (DDD)/1000

43 registrants, monthly prevalence and incidence of tramadol users, annual supply days

44 and mean daily dose of tramadol. Aggregated-level national statistics and prescribing

45 reimbursement data from 2004 to 2015 were also used to quantify annual and

46 monthly tramadol DDD/1000 inhabitants and rate of tramadol-related deaths in

47 England and Wales. Interrupted time-series analysis was used to evaluate the impact

48 of tramadol classification in June 2014.

\section{Results}

50 Prevalence of tramadol users increased from 23 to 97.6/10000 registrants from 2000

51 to 2015. Both annual dose and annual supply days of existing tramadol users were

52 higher than new users. Level and trend of monthly utilisation $\left(\beta_{2}:-12.9, \beta_{3}:-1.6\right)$ and

53 prevalence of tramadol users $\left(\beta_{2}:-6.4, \beta_{3}:-0.37\right)$ significantly reduced after 
1

2

3

4

5

6

7

8

10

11

12

13

14

15

16

17

18

19

20

21

22

23

24

25

26

27

28

29

30

31

32

33

34

35

36

37

38

39

40

41

42

43

44

45

46

47

48

49

50

51

52

53

54

55

56

57

58

59

60

54 classification. Both annual tramadol utilisation and rate of tramadol-related deaths

55 increased before tramadol classification, and decreased thereafter.

\section{Conclusions}

57 Increasing tramadol utilisation was influenced by the increase in prevalence and

58 incidence of tramadol users, mean daily dose and day of supply. Prevalence of

59 tramadol users, tramadol utilisation and reported deaths declined after tramadol

60 classification. Future studies need to evaluate the influencing factors to ensure the

61 safety of long-term tramadol use. 
62 Introduction

63 Tramadol is indicated for moderate to severe pain in the United Kingdom (UK).

64 In the past decade, the utilisation of tramadol has consistently increased in

65 many countries, including the United States (US), Germany ${ }^{1}$ as well as the

$66 \mathrm{UK}^{2}$. According to the UK National Health Service (NHS) Business Services

67 Authority (BSA), the annual tramadol utilisation in England increased from 5.9

68 to 11.1 million Defined Daily Doses (DDD) between 2005 and 2012²;

69 coincidently, there was a marked increase in the number of tramadol-related

70 deaths during the same period.

71

72 In the US, prolonged opioid use for persistent pain has been identified as the

73 main reason for increasing opioid utilisation, ${ }^{3}$ although several clinical

74 guidelines ${ }^{4-6}$ suggest the long-term opioid use for chronic non-cancer pain

75 (CNCP) remains controversial. ${ }^{7,8}$ However, the reasons attributable to the

76 increasing opioid utilisation, such as tramadol have not been investigated in

77 the UK.

78

79 Currently, there is no direct evidence to infer the relationship between

80 increasing tramadol utilisation and related mortality in the UK. At the 
81 population level, the NHS BSA only presented tramadol utilisation without

82 adjusting for population size, and tramadol utilisation in Wales was not

83 included in the report; ${ }^{2}$ but the published mortality figures from the Office for

84 National Statistics (ONS) covered both England and Wales. ${ }^{9}$ Consequently,

85 the correlation between tramadol utilisation and tramadol-related deaths has

86 not been established. ${ }^{2}$

87

88 Due to the concerns about safety and potential risk of misuse, tramadol was

89 classified as a Schedule 3 Controlled Substance in June 2014 in the U.K. ${ }^{2}$

90 Thereafter, tramadol prescribing needs to follow stricter prescription

91 requirements with clear defined dose and the maximum supply days should

92 not exceed 30 days $^{2}$. For such a medication with high usage and potential

93 harm, the effectiveness of policy intervention on utilisation and

94 tramadol-related mortality is an important public health issue. However, the

95 effect of tramadol classification has not been explored.

96

97 Therefore, this study aimed to develop hypotheses to explain the increasing

98 tramadol utilisation and evaluate policy changes in the UK. The objectives

99 were to (1) identify potential reasons for increasing tramadol utilisation from 
100 individual utilisation patterns; (2) evaluate the impact of tramadol classification

101 on prevalence of tramadol users and tramadol utilisation; and (3) explore the 102 trend between tramadol utilisation and tramadol-related deaths. 


\section{Methods}

104 Study design and data source

105 This cross-sectional study used several data sources which cover information from

106 different geographical region and time frames, including aggregated-level and

107 publically available data from the UK government sources as well as individual patient

108 data (IPD) from a UK primary care database to address multiple research questions

109 and compensate limitation of each database (Table 1).

110

111 To explore potential reasons for the increasing tramadol utilisation from individual

112 utilisation patterns, validate findings about the impact of tramadol classification on

113 monthly tramadol utilisation from aggregate-level data and evaluate the impact of

114 tramadol classification on prevalence of tramadol users and tramadol utilisation, a UK

115 primary care database, the Clinical Practice Research Datalink (CPRD) from January

1161993 to December 2015 was used after receiving approval from the Independent

117 Scientific Advisory Committee of the Medicines and Healthcare Products Regulatory 118 Agency (Protocol number: 12_007RA).

119

120 CPRD is the largest verified primary care database of anonymised clinical records in 121 the UK. IPD in CPRD were prospectively collected from general practitioners' daily 
122 records and it represents about $8.3 \%$ of the UK population up to March $2016 .^{10-12}$ The

123 population is representative of the UK general population in terms of the age and

124 gender distribution, and hence, CPRD has been widely used in drug utilisation

125 research in UK primary care. ${ }^{13,14}$

126

127 Monthly practice-level dispensing data from October 2010 to September 2015 was

128 used as the primary data source to evaluate the impact of tramadol classification on

129 monthly tramadol utilisation in England. ${ }^{15}$ To explore the correlation between annual

130 tramadol utilisation and tramadol-related deaths between 2004 and 2015, this study

131 used mortality data which is originally recorded by the International Classification of

132 Diseases-the tenth version (ICD-10) diagnosis $\operatorname{codes}^{9}$, annual aggregated-level

133 dispensing data from Prescription Cost Analysis (PCA) in England ${ }^{16}$ and Wales ${ }^{17}$ and

134 the annual number of mid-year population estimates from the $\mathrm{ONS}^{18}$. Those 135 aggregate-level data are publically available and use requires no ethical review.

$137<$ Insert Table 1>

138

139 Study population

140 For the IPD analysis, adult CPRD registrants (age $>18$ years) prescribed tramadol 
141 between January 2000 and December 2015 were included. For monthly

142 practice-level dispensing data, practices which issued any tramadol prescriptions

143 between October 2010 and September 2015 in England were included.

144

145 Outcomes measured using aggregated-level data

146 The annual number of tramadol-related deaths/100000 inhabitants and annual and

147 monthly DDDs of dispensed tramadol/1000 inhabitants were measured in

148 aggregated-level statistics and datasets. The number of tramadol related deaths was

149 directly extracted from government reports. ${ }^{9}$ The annual quantity of tramadol

150 preparations reported in the PCA was used to calculate the annual number of DDDs

151 dispensed in England ${ }^{16}$ and Wales $^{17}$. While the quantity of tramadol preparations

152 extracted from monthly practice-level dispensing data were used to calculate the

153 monthly number of DDDs dispensed in England. ${ }^{15}$

154

155 The annual number of tramadol-related deaths was divided by the mid-year number

156 of population in England and Wales and then multiplied by 100000 to calculate the

157 annual number of tramadol-related deaths/100000 inhabitants. The total dose of each

158 tramadol preparation was calculated by multiplying strength (in milligrams) and 159 quantity, and then summed in annual or monthly basis, and then divided by 300 (as 
160 defined by the World Health Organisation ${ }^{19}$ ) to calculate the number of DDDs of

161 tramadol. The annual or monthly DDD was adjusted by the mid-year number of

162 population $^{18}$ to derive the annual or monthly number of DDDs of dispensed

163 tramadol/1000 inhabitants.

164

165 Outcomes measured using individual patient data

166 The monthly prevalence and incidence of tramadol users/10000 registrants, monthly

167 DDDs/1000 registrants and annual supply days and mean daily dose for each

168 tramadol user were measured by using tramadol prescription records form CPRD.

169

170 Adult patients who received their first tramadol prescription during the study period

171 were identified as new tramadol users in that calendar year, and if the patients

172 received tramadol in the subsequence years, they will be classified as existing users

173 in the subsequence years. The number of new and existing tramadol users were

174 calculated in each calendar month, and adjusted by the total number of active

175 patients in the CPRD to derive the monthly incidence and prevalence of tramadol

176 users/10000 registrants.

177

178 The total dose of each tramadol prescription was calculated by multiplying strength 
179 and quantity, and then converted to the monthly number of DDDs; which was further 180 adjusted by the number of active patients in the particular calendar month to calculate 181 the monthly number of DDDs of tramadol/1000 registrants.

182

183 For each tramadol prescription, the dose was divided by numerical daily dose 184 (recorded by physicians and available in the CPRD therapy file) to derive the number 185 of supply days. If the interval between two consecutive prescriptions was shorter than 186 the supply day of the anterior prescription, then the supply day was replaced by 187 interval between the two prescriptions.

188

189 For each patient, the total doses of tramadol prescriptions and annual number of 190 supply days were summed in each calendar year. If the annual number of supply 191 days was more than 365 days, then it was capped to 365 days. The annual dose was 192 divided by annual number of supply days to derive the annual mean daily dose in 193 particular calendar year.

194

195 Data analysis

196 Descriptive statistics were used to report annual dose and number of supply days.

197 The trend of (1) monthly incidence and prevalence of tramadol users from January 
1982000 to December 2015; (2) annual mean daily dose stratified by new and existing

199 users; (3) annual number of DDDs of dispensed tramadol/1000 inhabitants and the 200 rate of tramadol-related deaths in England and Wales from 2004 to 2015 were 201 reported graphically. Cross-correlation between the two time-series, i.e. annual 202 number of tramadol-related deaths/100000 inhabitants and annual number of DDDs 203 of dispensed tramadol/1000 inhabitants, was investigated at no lag time effect and 204 presented as cross-correlation coefficient (ranged from -1 to 1).

205

206 Interrupted time-series analysis (ITSA $)^{20}$ was used to evaluate the impact of tramadol 207 classification in June 2014 on the levels and trends of two series between October 2082010 and September 2015: (1) monthly prevalence and incidence of tramadol users 209 estimated from CPRD; (2) monthly DDD/1000 registrants estimated from both 210 monthly practice-level dispensing data and CPRD. In CPRD, monthly DDD/1000 211 registrants was further stratified by new and existing users to identify the impact of 212 tramadol classification on different patient groups.

213

214 The Durbin Watson test was used to test first-order autocorrelation in each time 215 series, as no first-order autocorrelation was found ${ }^{21}$, and hence auto-regressive 216 integrated moving-average (ARIMA) model was not applied in the ITSA ${ }^{22}$. In the 
Page 15 of 44

Pharmacoepidemiology and Drug Safety

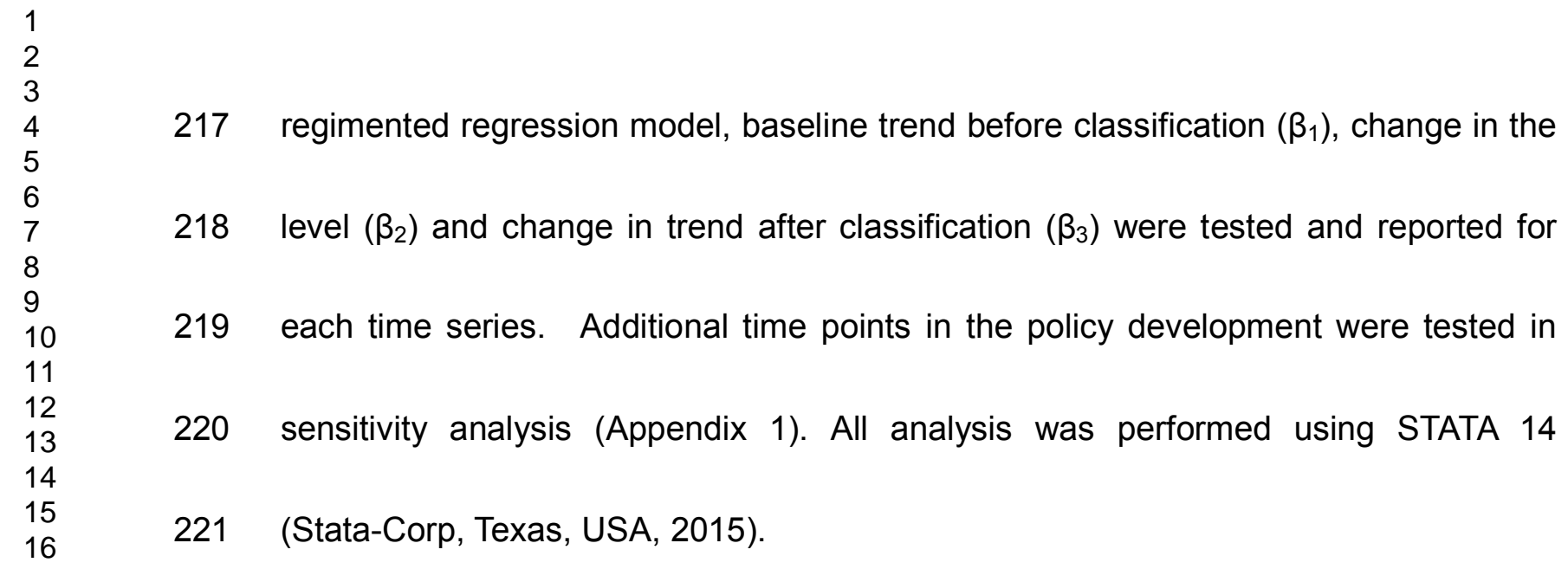

16

17

18

19

20

21

22

23

24

25

26

27

28

29

30

31

32

33

34

35

36

37

38

39

40

41

42

43

44

45

46

47

48

49

50

51

52

53

54

55

56

57

58

59
60

14

http://mc.manuscriptcentral.com/pds 


\section{Results}

\section{Trend of prevalence and incidence of tramadol users from 2000 to 2015}

224 The IPD extracted from CPRD showed that the monthly prevalence and incidence of

225 tramadol users increased from 23 to $99.3 / 10000$ registrants and 4.1 to $7.7 / 10000$

226 registrants respectively between January 2000 and May 2014 (Figure 1).

227

$228<$ Insert Figure 1>

229

230 Annual dose, supply days and mean daily dose from 2000 to 2015

231 For all adult tramadol users in CPRD, most tramadol prescriptions were issued for 232 existing tramadol users. In $2000,69.2 \%$ of the annual tramadol dose was prescribed 233 to existing tramadol users, and this proportion increased to $91.4 \%$ in 2015 (Appendix 234 2). In addition, between 2000 and 2015, the annual dose per existing tramadol user in 235 each calendar year (range: 37910.8 to $40218.2 \mathrm{mg}$ ) was consistently higher than the 236 annual dose per new users (range: 9717.8 to $11642.6 \mathrm{mg}$ ). Furthermore, the annual 237 supply days per existing tramadol users in each calendar year (range: 134.3 to 150.7 238 days) was consistently higher than new users (range: 35.7 to 47.9 days) (Appendix $2393)$.

240

241 From 2000 to 2013, the annual mean daily tramadol dose increased in both existing 
242 and new users. After 2007, new users had greater annual mean daily dose than

243 existing users, however, since tramadol classification, the annual mean daily dose of

244 new users decreased in 2014 and 2015 (Figure 2).

245

$246<$ Insert Figure 2>

247

248 Impact of tramadol classification on monthly tramadol utilisation

249 Tramadol classification had similar impacts on its utilisation in the results of ITSA 250 using aggregated-level data and IPD. In the monthly practice-level dispensing data, 251 the ITSA revealed that the level $\left(\beta_{2}:-12.9, p=0.017\right)$ and the trend $\left(\beta_{3}:-1.6, p=0.002\right)$ 252 of monthly tramadol utilisation significantly decreased after tramadol classification, 253 despite there was a significant increase in the baseline trend $\left(\beta_{1}: 0.79, p<0.001\right)$ 254 before tramadol classification (Figure 3).

255

$256<$ Insert Figure 3>

257

258 Similarly, the IPD from CPRD showed a significant increase trend $\left(\beta_{1}: 0.56, p<0.001\right)$

259 before tramadol classification, and the level significantly reduced at the launch of 260 classification $\left(\beta_{2}:-16.3, p=0.021\right)$ but there was no significant change in the trend of 
261 tramadol utilisation after classification.

262

263 When stratifying monthly tramadol utilisation into existing and new tramadol users, 264 before the classification, the trend significantly increased in existing users $\left(\beta_{1}: 0.63\right.$, $265 p<0.001)$ (Figure 4) but decreased in new users $\left(\beta_{1}:-0.07, p<0.001\right)$ (Figure 5). After 266 the launch of tramadol classification, the level significantly decreased in both existing 267 users $\left(\beta_{2}:-13.8, p=0.041\right)$ and new $\left(\beta_{2}:-2.6, p<0.001\right)$ users. However, there was no 268 significant change in the trend of tramadol utilisation for both existing and new users 269 after tramadol classification.

270

$271<$ Insert Figure 4>

272

$273<$ Insert Figure 5>

274

275 Impact of tramadol classification on monthly prevalence and incidence of 276 tramadol users

277 In addition to the decrease in monthly tramadol utilisation, tramadol classification also 278 decreased the prevalence of tramadol users. In the IPD from CPRD, the baseline 279 trend significantly increased in prevalence $\left(\beta_{1}: 0.21, p<0.001\right)$ but decreased in 
280 incidence $\left(\beta_{1}:-0.04, p<0.001\right)$ of tramadol users between October 2010 and May 281 2014. The level of both prevalence $\left(\beta_{2}:-6.4, p=0.001\right)$ and incidence $\left(\beta_{2}:-1.7\right.$, $282 \mathrm{p}<0.001)$ decreased significantly after the launch of tramadol classification. However, 283 only the trend of prevalence decreased significantly $\left(\beta_{3}:-0.37, p=0.028\right)$ and there 284 was no significant change in the trend of incidence (Figure 1). All sensitivity analysis 285 models found that other intervention time points had no significant effect on tramadol 286 utilisation, prevalence and incidence.

287 288 289 2014

290 Before tramadol classification, the annual tramadol utilisation summarised in PCA in 291 England and Wales increased from 1190.4 to 2714.7 DDDs/1000 inhabitants during 2922004 and 2013; meanwhile the number of tramadol-related deaths/100000 293 inhabitants increased from 0.08 in 2004 to 0.42 in 2014 (Figure 6). After tramadol 294 classification, tramadol annual utilisation decreased, and the number of 295 tramadol-related deaths $/ 100000$ inhabitants decreased to 0.36 in 2015 . A strong 296 positive correlation was found between tramadol annual utilisation and related deaths 297 (cross-correlation coefficient=0.9090). 
1

2

3

4

5

6

7

8

9

10

11

12

13

14

15

16

17

18

19

20

21

22

23

24

25

26

27

28

29

30

31

32

33

34

35

36

37

38

39

40

41

42

43

44

45

46

47

48

49

50

51

52

53

54

55

56

57

58

59

60

$299<$ Insert Figure 6> 


\section{Discussion}

301 This study found monthly tramadol utilisation consistently increased before tramadol

302 classification and the increasing trend did not act as a substitution of other more

303 potent opioids because the utilisation of all strong opioids and codeine consistently

304 increased since $2004 .^{2}$ Furthermore, the withdrawal of co-proxamol in 2005 did not

305 change the increasing trend of tramadol utilisation and tramadol-related death from

$3062000 .{ }^{23}$

307

308 From the IPD, the monthly incidence of tramadol users doubled and the monthly

309 prevalence increased four-fold. The mean daily dose of tramadol prescriptions

310 increased and more than $70 \%$ of tramadol users were existing users who had greater

311 number of supply days than new users. Therefore, the increasing prevalence and

312 incidence of tramadol users, higher mean daily dose and the prolonged use of

313 tramadol were the main causes of increasing tramadol utilisation over time.

314

315 From the monthly practice-level dispensing data, the monthly tramadol utilisation

316 decreased after tramadol classification. Once tramadol users were stratified into new

317 and existing users in the IPD, the level of tramadol utilisation and the prevalence of

318 tramadol users decreased after classification, but only the trend of prevalence of 
319 tramadol users changed significantly after June 2014.

320

321 Overall, a similar trend between annual tramadol utilisation and the rate of 322 tramadol-related deaths was found, which is consistent with government 323 publications. ${ }^{2}, 9$ In short, after the launch of tramadol classification, monthly 324 prevalence and incidence, overall tramadol utilisation and the number of 325 tramadol-related deaths decreased reversing the upward trend from 2004.

326

327 The increasing tramadol utilisation may be attributed to long-term opioid utilisation 328 which is commonly observed in patients with CNCP. ${ }^{3}$ In the UK, higher does and 329 prolonged use of strong opioids was related to increasing demands for pain relief in $330 \mathrm{CNCP}^{24}$ In addition, a cross-sectional study conducted in Germany found that higher 331 tramadol utilisation was associated with CNCP diagnosis. ${ }^{1}$ However, similar to other 332 opioids, there is currently no robust evidence to support the clinical effectiveness of 333 prolonged tramadol utilisation for CNCP. ${ }^{25-28}$ Moreover, evidence from post-mortem 334 toxicological analysis in the UK suggests that tramadol-related deaths were more 335 related to persistent tramadol users. ${ }^{29-31}$

336

337 Nevertheless, the ITSA found tramadol classification did not change the increasing 
338 trend of tramadol utilisation in existing tramadol users who had greater number of 339 supply days. In addition, the proportion of tramadol-related deaths in all opioid-related 340 deaths (10.5\%) was still higher than codeine-related deaths $(6.4 \%)$ in 2015 , despite 341 more prescriptions for codeine being dispensed. ${ }^{9}$

342

343 Although indicators to monitor tramadol related deaths are needed, as tramadol has

344 been considered relatively safe comparing with other strong opioids ${ }^{8}$, only one of the 345 previous nested case-control studies which assessed the association between risk 346 factors and opioid-related deaths included tramadol. ${ }^{7,8,32}{ }^{33}$ Furthermore, tramadol 347 related deaths involved multiple risk factors ${ }^{29-31}$, but there is currently no applicable 348 indicators to monitor tramadol utilisation and related deaths.

349

350 In the ITSA, the decreased trend in monthly tramadol utilisation was found in the 351 aggregated monthly practice-level dispensing data but not in IPD. Some reasons 352 might explain the different results derived from the two data sources. First, CPRD 353 contains prescribing records from general practices, but NHS Digital data included 354 community dispensing records, and prescriptions are not necessary always been 355 dispensed. Second, CPRD collects prescription records from selected practices 356 across the UK whereas NHS Digital obtains all dispensing data in England. There 
357 might be some variations in patients' characteristics and prescribers' clinical decision 358 making between practices in CPRD and NHS Digital dispensing data. In fact, 359 geographic variation in opioid prescribing has been found in the USA and 360 Australia ${ }^{34-36}$, and it was possible that the interpretation and application of policy 361 varied between practices in different regions.

362

363 This is the first study to identify the influence of tramadol classification on its utilisation 364 in the UK. To fully explore tramadol utilisation in the past 15 years, several national 365 statistics and datasets as well as CPRD were used to compensate the limitations of 366 each database. We used DDDs to quantify tramadol utilisation which is easy to 367 compare with previous studies and understand the clinical implication as it can be 368 converted into oral morphine equivalent dose by multiplying the potency ratio. ${ }^{37}$ 369 Furthermore, to establish hypotheses for further analysis, potential reasons of 370 increasing tramadol utilisation and tramadol-related deaths were identified by 371 measuring both individual and population utilisation.

373 There are some limitations to this research. CPRD does not included prescription 374 records from secondary care and hence may underestimate tramadol utilisation, 375 especially for acute tramadol use. Tramadol prescriptions outside the study period 
376 were not included and hence the new users might be over-estimated. Furthermore,

377 this cross-sectional study aimed to establish potential hypotheses for changes in

378 tramadol utilisation and deaths, but it was not intended to study the causal

379 relationship between particular utilisation patterns such as chronic use and changes

380 in tramadol utilisation. The number of tramadol-related deaths was an aggregated

381 summary retrieved from government reports and hence characteristics of

382 tramadol-related fatalities were not available to be explore.

383

384 In conclusion, the prolonged use by existing tramadol users and the increasing 385 prevalence of tramadol users led to increasing tramadol utilisation over the past 386 fifteen years in the UK. Although tramadol classification altered tramadol utilisation 387 and associated deaths, to optimise the use of tramadol in patients with CNCP, future 388 studies are needed to identify the causal relationship between patient characteristics, 389 long-term tramadol utilisation and tramadol-related deaths. 


\section{References}

392 1. Tholen $\mathrm{K}$ and Hoffmann F. High use of tramadol in Germany: an analysis of statutory 393 health insurance data. Pharmacoepidemiol Drug Saf 2012; 21: 1013-21. DOI: 394 10.1002/pds.3266

395 2. Advisory Council on the Misuse of Drugs. Advisory Council on the Misuse of Drugs 396 consideration of tramadol. 2013; 397 https://www.gov.uk/government/uploads/system/uploads/attachment data/file/144116/advice 398 -tramadol.pdf [accessed 02 June 2014]

399 3. Sullivan MD, Edlund MJ, Fan MY, et al. Trends in use of opioids for non-cancer pain 400 conditions 2000-2005 in commercial and Medicaid insurance plans: the TROUP study. Pain 401 2008; 138: 440-9. DOI: 10.1016/j.pain.2008.04.027

402 4. Hauser W, Bock F, Engeser P, et al. Long-term opioid use in non-cancer pain. Dtsch 403 Arztebl Int 2014; 111: 732-40. DOI: 10.3238/arztebl.2014.0732

404 5. Manchikanti L, Abdi S, Atluri S, et al. American Society of Interventional Pain Physicians 405 (ASIPP) guidelines for responsible opioid prescribing in chronic non-cancer pain: Part 406 2--guidance. Pain Physician 2012; 15: S67-116.

407 6. Public Health England. Opioids Aware: A resource for patients and healthcare 408 professionals to support prescribing of opioid medicines for pain. . 2016; 409 https://www.fpm.ac.uk/faculty-of-pain-medicine/opioids-aware [accessed 02 October 2016]

410 7. Bohnert $\mathrm{AS}$, Valenstein $\mathrm{M}$, Bair $\mathrm{MJ}$, et al. Association between opioid prescribing 411 patterns and opioid overdose-related deaths. JAMA 2011; 305: 1315-21. DOI: 412 10.1001/jama.2011.370.

413 8. Dunn KM, Saunders KW, Rutter CM, et al. Opioid prescriptions for chronic pain and 414 overdose: a cohort study. Ann Intern Med 2010; 152: 85-92. DOI: 415 10.7326/0003-4819-152-2-201001190-00006

416 9. Office for National Statistics. Deaths related to drug poisoning in England and Wales, $4172015 \quad$ registrations. 2016; 418 www.ons.gov.uk/peoplepopulationandcommunity/birthsdeathsandmarriages/deaths/bulletins/ 419 deathsrelatedtodrugpoisoninginenglandandwales/2015registrations/pdf $\quad$ [accessed 9 420 September 2016]

421 10. Clinical Practice Research Datalink. Release notes - CPRD GOLD March 2016. . March 
422 2016; https://cprdcw.cprd.com/downloads/FileDownloads.aspx [accessed 23 March 2016]

423 11. Garcia Rodriguez LA and Perez Gutthann S. Use of the UK General Practice Research 424 Database for pharmacoepidemiology. Br J Clin Pharmacol 1998; 45: 419-25.

425 12. Williams $\mathrm{T}$, van Staa $\mathrm{T}$, Puri $\mathrm{S}$, et al. Recent advances in the utility and use of the 426 General Practice Research Database as an example of a UK Primary Care Data resource. 427 Ther Adv Drug Saf 2012; 3: 89-99. DOI: 10.1177/2042098611435911

428 13. Baker A, Chen LC, Elliott RA, et al. The impact of the 'Better Care Better Value' 429 prescribing policy on the utilisation of angiotensin-converting enzyme inhibitors and 430 angiotensin receptor blockers for treating hypertension in the UK primary care setting: 431 longitudinal quasi-experimental design. BMC Health Serv Res 2015; 15: 367. DOI: 432 10.1186/s12913-015-1013-y

433 14. Taylor A, Chen LC and Smith MD. Adherence to inhaled corticosteroids by asthmatic 434 patients: measurement and modelling. Int $J$ Clin Pharm 2014; 36: 112-9. DOI: 435 10.1007/s11096-013-9862-0

436 15. NHS Digital. General practitioner practice prescribing presentation-level Data. 437 http://content.digital.nhs.uk/searchcatalogue?topics=1\%2fPrescribing\%2fPrimary+care+pres 438 cribing\&sort=Relevance\&size=10\&page=1\#top [accessed February 2016]

439 16. NHS Digital. Prescription Cost Analysis England: 2004-2015. 440 http://content.digital.nhs.uk/searchcatalogue?topics=1\%2fPrescribing\%2fPrimary+care+pres 441 cribing\&sort=Relevance\&size=10\&page=1\#top [accessed March 2016]

442 17. NHS Wales Shared Services Partnership. Prescription cost analysis: Individual 443 preparations, 2004-2015.

444 http://gov.wales/statistics-and-research/prescriptions-dispensed-community/?lang=en 445 [accessed March 2016]

446 18. Office for National Statistics. Annual Mid-year Population Estimates: 2004-2015. 447 https://www.ons.gov.uk/peoplepopulationandcommunity/populationandmigration/populatione 448 stimates [accessed June 2016]

449 19. World Health Organization. Anatomical therapeutic chemical / defined daily dose index 450 2016. . March 2016; http://www.whocc.no/atc ddd index/ [accessed 10 April 2016 ]

451 20. Wagner AK, Soumerai SB, Zhang F, et al. Segmented regression analysis of interrupted 452 time series studies in medication use research. J Clin Pharm Ther 2002; 27: 299-309. DOI: $453 \quad 10.1046 / j .1365-2710.2002 .00430 . x$ 
454 21. Durbin $\mathrm{J}$ and Watson GS. Testing for serial correlation in least squares regression. I. 455 Biometrika 1950; 37: 409-28.

456 22. Box EP and Jenkins GM. Time series analysis. London: Holden-Day; 1976.

457 23. Hawton $\mathrm{K}$, Bergen $\mathrm{H}$, Simkin $\mathrm{S}$, et al. Effect of withdrawal of co-proxamol on prescribing 458 and deaths from drug poisoning in England and Wales: time series analysis. BMJ 2009; 459 338:b2270.: 10.1136/bmj.b2270. DOI: 10.1136/bmj.b2270

460 24. Zin CS, Chen LC and Knaggs RD. Changes in trends and pattern of strong opioid 461 prescribing in primary care. European Journal of Pain 2014; 18: 1343-51. DOI: 462 10.1002/j.1532-2149.2014.496.x

463 25. Chaparro LE, Furlan AD, Deshpande A, et al. Opioids compared with placebo or other 464 treatments for chronic low back pain: an update of the Cochrane Review. Spine (Phila Pa 465 1976) 2014; 39: 556-63. DOI: 10.1097/brs.0000000000000249

466 26. Furlan AD, Sandoval JA, Mailis-Gagnon A, et al. Opioids for chronic noncancer pain: a 467 meta-analysis of effectiveness and side effects. CMAJ 2006; 174: 1589-94. DOI: $468 \quad 10.1503 / \mathrm{cmaj} .051528$

469 27. Hollingshead J, Duhmke RM and Cornblath DR. Tramadol for neuropathic pain. 470 Cochrane Database Syst Rev 2006; 19. DOI: 10.1002/14651858.CD003726.pub3

471 28. Mariconti $\mathrm{P}$ and Collini R. Tramadol SR in arthrosic and neuropathic pain. Minerva 472 Anestesiol 2008; 74: 63-8.

473 29. Hakkinen M, Launiainen $\mathrm{T}$, Vuori E, et al. Comparison of fatal poisonings by prescription 474 opioids. Forensic Sci Int 2012; 222: 327-31. DOI: 10.1016/j.forsciint.2012.07.011

475 30. Tjaderborn M, Jonsson AK, Hagg S, et al. Fatal unintentional intoxications with tramadol 476 during 1995-2005. Forensic Sci Int 2007; 173: 107-11. DOI: 10.1016/j.forsciint.2007.02.007

477 31. Randall $C$ and Crane J. Tramadol deaths in Northern Ireland: a review of cases from 4781996 to 2012. J Forensic Leg Med 2014; 23: 32-6. DOI: 10.1016/j.jflm.2014.01.006

479 32. Gomes T, Mamdani MM, Dhalla IA, et al. Opioid dose and drug-related mortality in 480 patients with nonmalignant pain. Arch Intern Med 2011; 171: 686-91. DOI: 481 10.1001/archinternmed.2011.117

482 33. Liang $\mathrm{Y}$ and Turner BJ. Assessing risk for drug overdose in a national cohort: role for 483 both daily and total opioid dose? J Pain 2015; 16: 318-25. DOI: 10.1016/j.jpain.2014.11.007 
1

2

3

4

5

6

7

8

9

10
484 34. McDonald DC and Carlson KE. The ecology of prescription opioid abuse in the USA: 485 geographic variation in patients' use of multiple prescribers ("doctor shopping"). 486 Pharmacoepidemiol Drug Saf 2014; 23: 1258-67. DOI: 10.1002/pds.3690

487 35. Degenhardt L, Gisev N, Cama E, et al. The extent and correlates of community-based 488 pharmaceutical opioid utilisation in Australia. Pharmacoepidemiology and drug safety 2016; 489 25: 521-38. DOI: 10.1002/pds.3931

490 36. McDonald DC, Carlson K and Izrael D. Geographic variation in opioid prescribing in the 491 U.S. J Pain 2012; 13: 988-96. DOI: 10.1016/j.jpain.2012.07.007

492 37. Svendsen K, Borchgrevink P, Fredheim O, et al. Choosing the unit of measurement 493 counts: the use of oral morphine equivalents in studies of opioid consumption is a useful 494 addition to defined daily doses. Palliat Med 2011; 25: 725-32.

496

497 
Table

\section{Table 1. A summary of aggregated-level data and individual patient data used in this study}

\begin{tabular}{|c|c|c|c|c|}
\hline Data source & Dataset & Countries and time & Extract information & Outcome measure \\
\hline \multicolumn{5}{|c|}{ Aggregated-level statistics and datasets } \\
\hline ONS & $\begin{array}{l}\text { Deaths related to drug } \\
\text { poisoning }^{9}\end{array}$ & $\begin{array}{l}\text { England and Wales, } \\
\text { 2004-2015 }\end{array}$ & $\begin{array}{l}\text { Annual number of } \\
\text { tramadol-related deaths }\end{array}$ & $\begin{array}{l}\text { Annual number of tramadol-related deaths/ } \\
100000 \text { inhabitants }\end{array}$ \\
\hline ONS & $\begin{array}{l}\text { Annual number of mid-year } \\
\text { population estimates }^{18}\end{array}$ & $\begin{array}{l}\text { England and Wales, } \\
\text { 2004-2015 }\end{array}$ & $\begin{array}{l}\text { Annual number of mid-year } \\
\text { population estimates }\end{array}$ & $\begin{array}{l}\text { Annual and monthly DDD/1000 inhabitants } \\
\text { Annual number of tramadol-related deaths/ } \\
100000 \text { inhabitants }\end{array}$ \\
\hline NHS Digital & $\begin{array}{l}\text { Annual Prescription Cost } \\
\text { Analysis }^{16}\end{array}$ & England, 2004-2015 & $\begin{array}{l}\text { Annual quantity of dispensed } \\
\text { tramadol preparations }\end{array}$ & Annual DDD/1000 inhabitants \\
\hline NHS Wales* & $\begin{array}{l}\text { Annual Prescription Cost } \\
\text { Analysis }^{17}\end{array}$ & Wales, 2004-2015 & $\begin{array}{l}\text { Annual quantity of dispensed } \\
\text { tramadol preparations }\end{array}$ & Annual DDD/1000 inhabitants \\
\hline NHS Digital & $\begin{array}{l}\text { Monthly practice-level } \\
\text { dispensing data }^{15}\end{array}$ & $\begin{array}{l}\text { England, October } 2010 \\
\text { to September } 2015\end{array}$ & $\begin{array}{l}\text { Monthly quantity of dispensed } \\
\text { tramadol preparations }\end{array}$ & Monthly DDD/1000 inhabitants \\
\hline \multicolumn{5}{|c|}{ Individual patient data } \\
\hline CPRD & Therapy file & $\begin{array}{l}\text { United Kingdom, } \\
\text { January } 1993 \text { to } \\
\text { December } 2015\end{array}$ & Tramadol prescriptions & $\begin{array}{l}\text { Monthly DDD/1000 registrants } \\
\text { Monthly incidence and prevalence/10000 } \\
\text { registrants } \\
\text { Annual supply days and mean daily dose }\end{array}$ \\
\hline
\end{tabular}




\section{Figure}

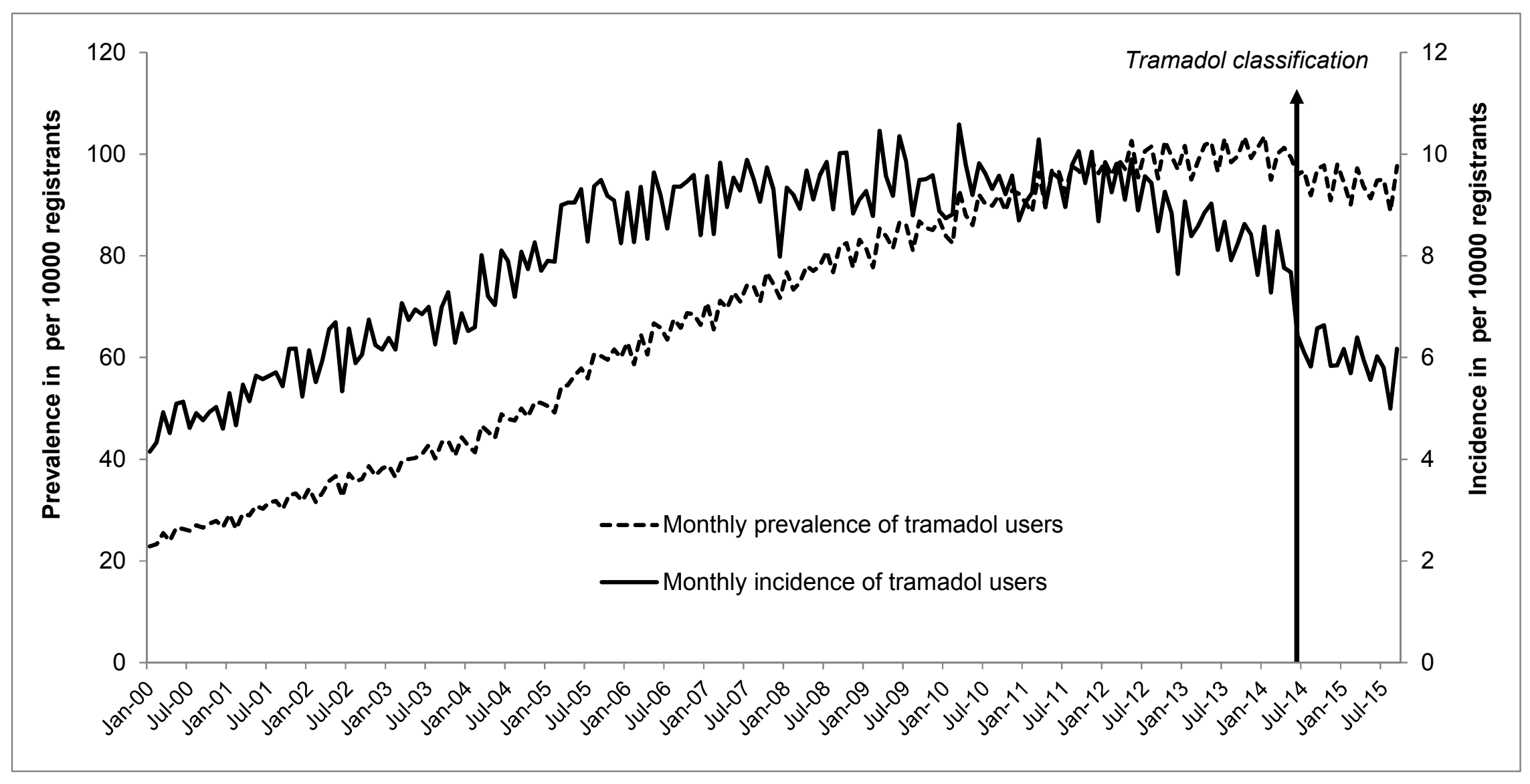

Figure 1. Monthly prevalence and incidence of tramadol users per 10000 registrants between 2000 and 2015 


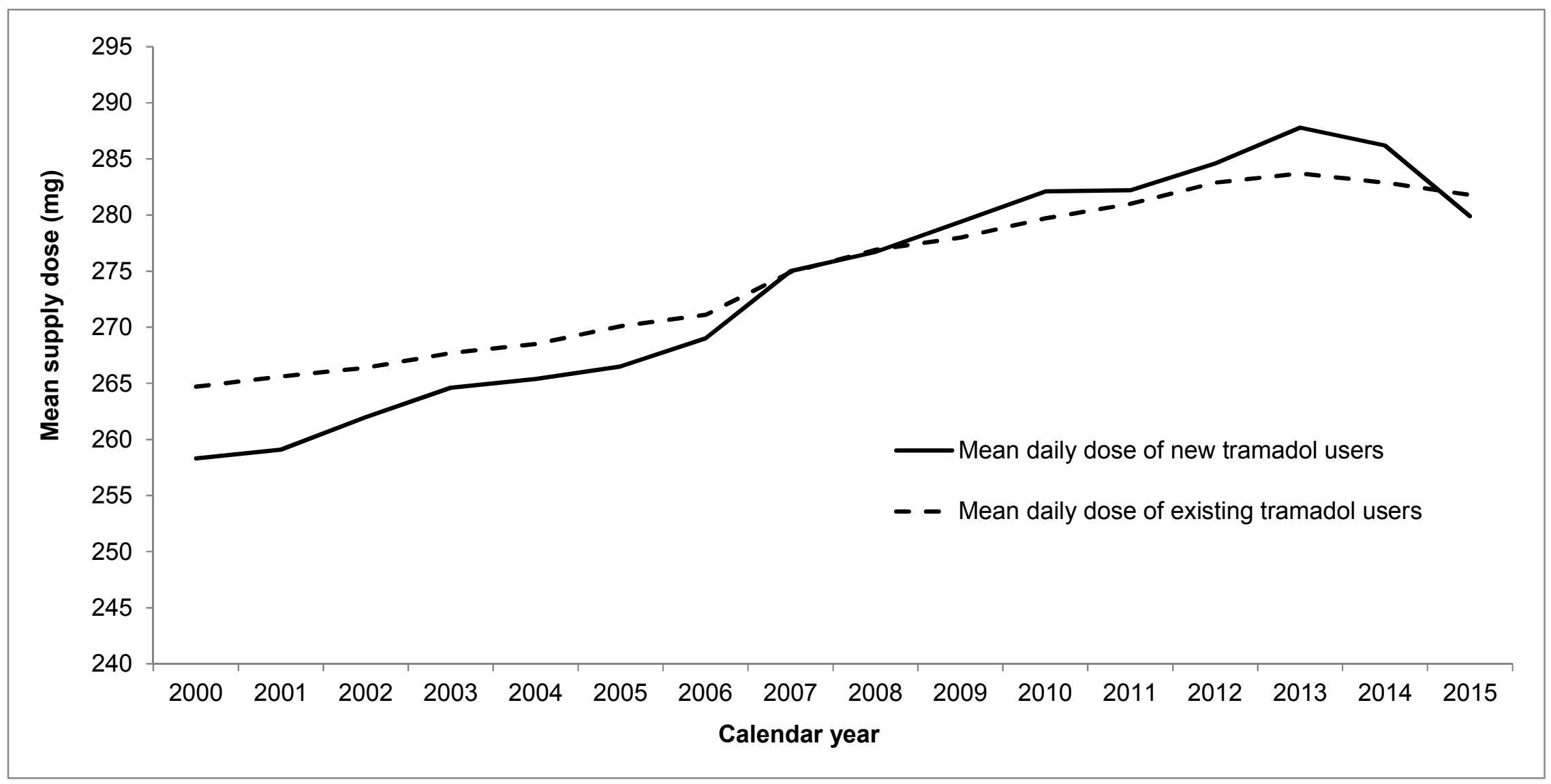

Figure 2. Mean daily dose between existing and new tramadol users 


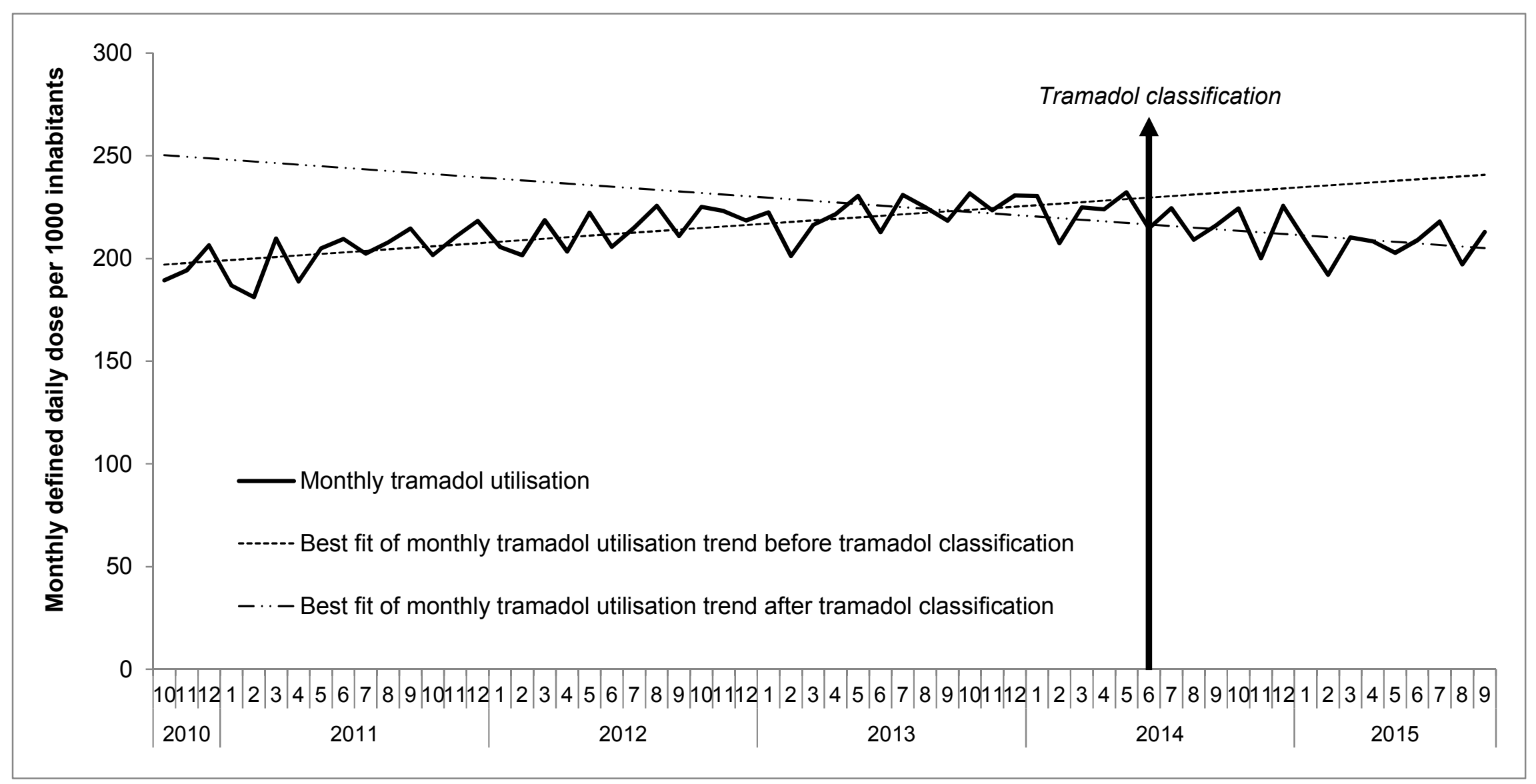

Figure 3. Monthly tramadol utilisation in England between October 2010 and September 2015 in the national practice-level dispensing data 


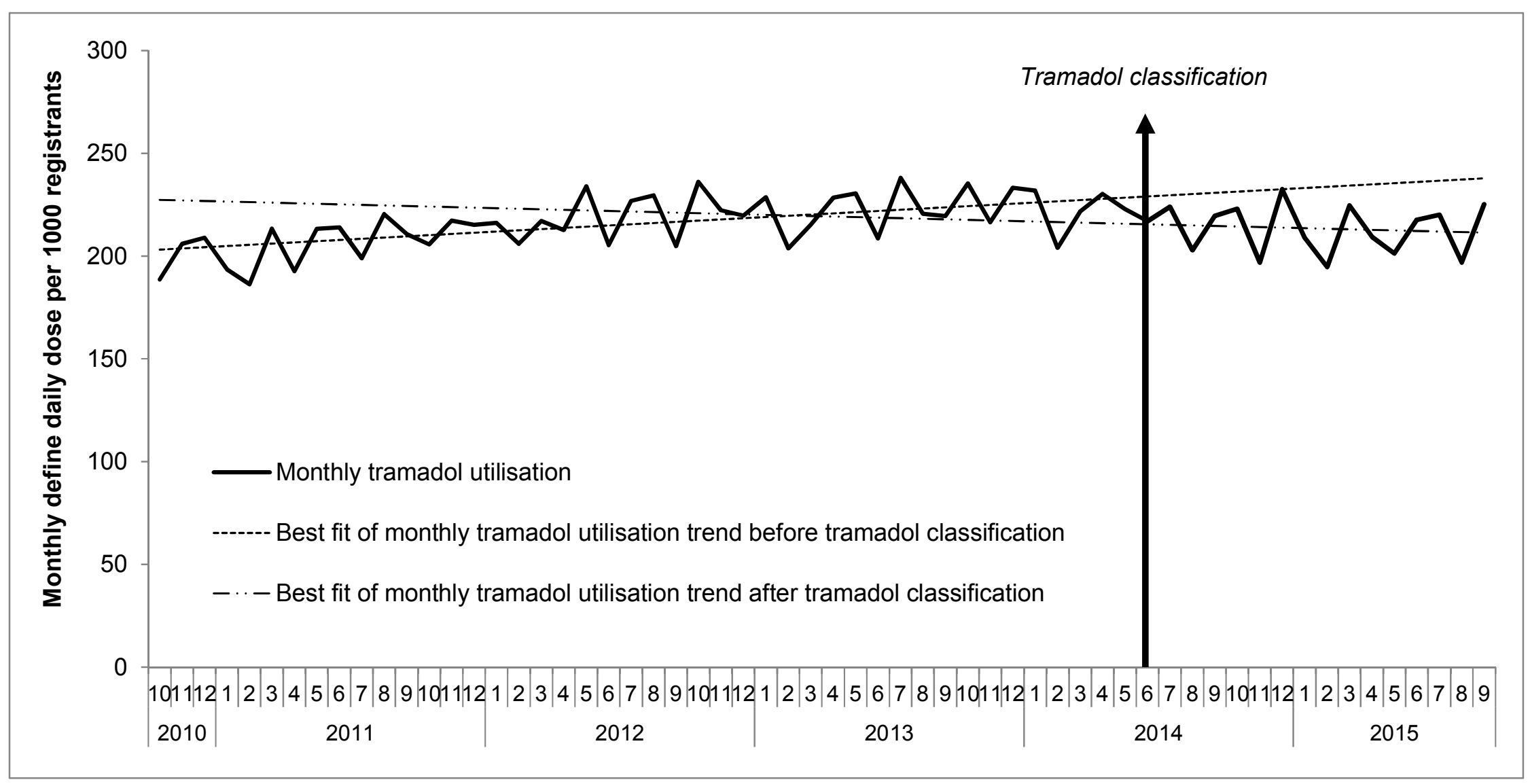

Figure 4. Monthly tramadol utilisation for existing tramadol users between October 2010 and September 2015 in the individual patient data retrieved from CPRD 


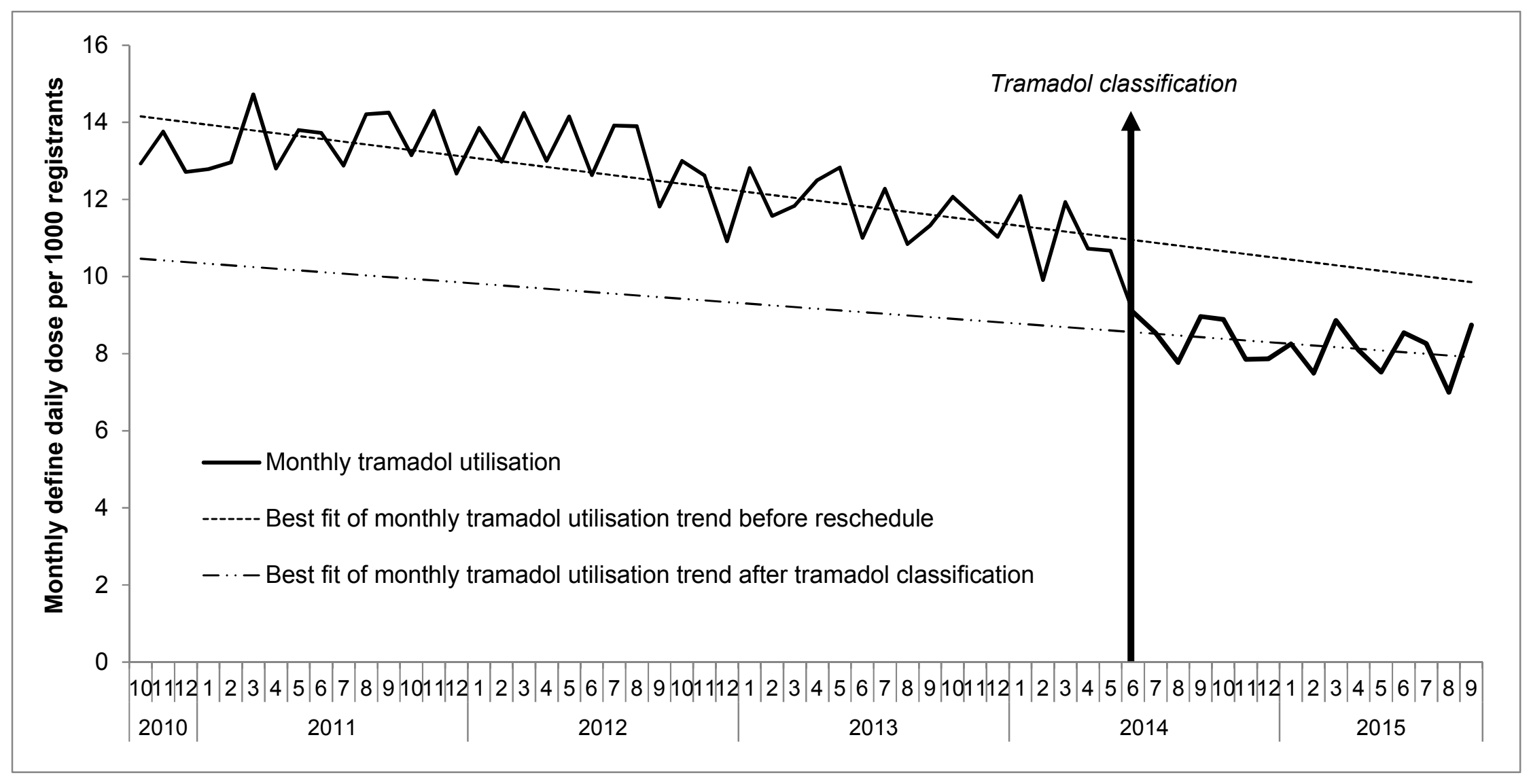

Figure 5. Monthly tramadol utilisation for new tramadol users between October 2010 and September 2015 in the individual patient data retrieved from CPRD 


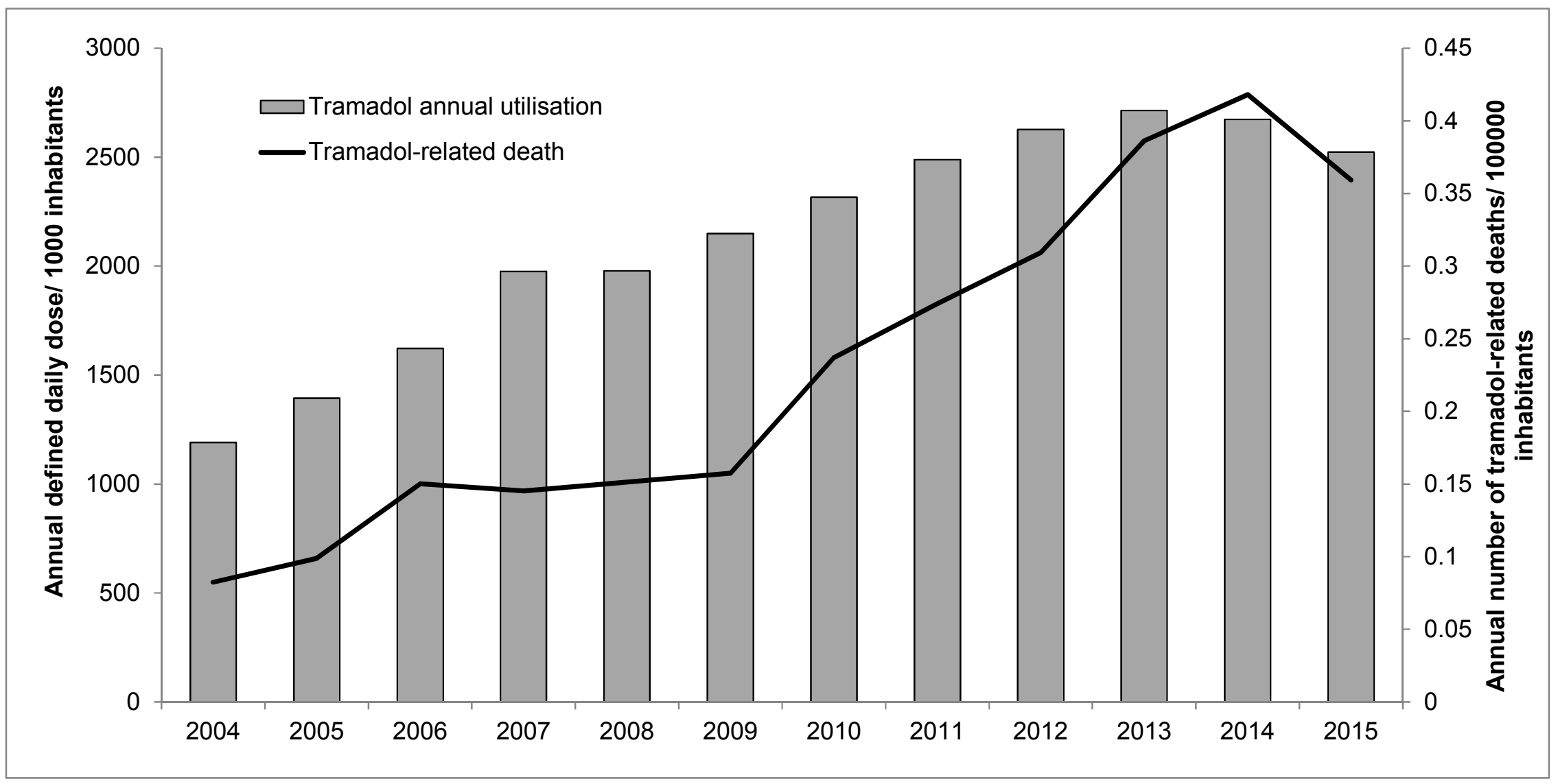

Figure 6. Annual tramadol utilisation and the number of tramadol-related deaths in England and Wales from 2004 to 2015 


\section{Corresponding author only (Co-authors go to Question 4):}

POTENTIAL STUDY INTERPRETATION CONFLICTS

1. Some or all of the data that were used in this study were provided by a company with a vested interest in the product being studied.

$n / a$

2. The sponsor of this project had the right of commenting but the authors retained the right to accept or reject comments or suggestions.

$\mathrm{n} / \mathrm{a}$

3. The sponsor of this project had the right of final editing and/or approval of the manuscript submitted.

$\mathrm{n} / \mathrm{a}$

\section{Corresponding author and Co-authors:}

POTENTIAL FINANCIAL CONFLICTS

4. I, my spouse, or one of my dependent children is an employee of a company whose product is being studied.

No

5. I, my spouse, or one of my dependent children has significant equity interest (>USD 10,000) in the company that owns the product being studied.

No 
6. In the past three years I have:

- been paid as a consultant (or in a similar capacity) by a company with a vested interest in the product being studied, on issues related to the product being studied; No

- been paid as a consultant (or in a similar capacity by a company with a vested interest in the product being studies, on issues unrelated to the product being studied; No

- received research or educational support from a company with a vested interest in the product(s) being studied.

No

7. A company whose product is being studied has provided funding to support the work on this project.

No

If you have answered YES to any of the above questions, or if you have additional personal, commercial or academic conflicts of interest, please draft a statement to publish with the article. e.g., AB has been reimbursed by Safe Drug Ltd. for international conference attendance.

8. Manuscript title (first six words are sufficient)

A fifteen-year overview of increasing tramadol utilisation and associated mortality and the impact of tramadol classification in the United Kingdom

9. Author's full name (a separate form must be submitted for each author)

\section{Teng-Chou Chen}

10. In checking this box, I confirm I have completed this form to the best of my knowledge. $\bigotimes$

This form is available online by clicking here 


\section{Corresponding author only (Co-authors go to Question 4):}

POTENTIAL STUDY INTERPRETATION CONFLICTS

1. Some or all of the data that were used in this study were provided by a company with a vested interest in the product being studied.

$n / a$

2. The sponsor of this project had the right of commenting but the authors retained the right to accept or reject comments or suggestions.

$\mathrm{n} / \mathrm{a}$

3. The sponsor of this project had the right of final editing and/or approval of the manuscript submitted.

$\mathrm{n} / \mathrm{a}$

\section{Corresponding author and Co-authors:}

POTENTIAL FINANCIAL CONFLICTS

4. I, my spouse, or one of my dependent children is an employee of a company whose product is being studied.

No

5. I, my spouse, or one of my dependent children has significant equity interest (>USD 10,000) in the company that owns the product being studied.

No 
6. In the past three years I have:

- been paid as a consultant (or in a similar capacity) by a company with a vested interest in the product being studied, on issues related to the product being studied; No

- been paid as a consultant (or in a similar capacity by a company with a vested interest in the product being studies, on issues unrelated to the product being studied; No

- received research or educational support from a company with a vested interest in the product(s) being studied.

No

7. A company whose product is being studied has provided funding to support the work on this project.

No

If you have answered YES to any of the above questions, or if you have additional personal, commercial or academic conflicts of interest, please draft a statement to publish with the article. e.g., AB has been reimbursed by Safe Drug Ltd. for international conference attendance.

8. Manuscript title (first six words are sufficient)

A fifteen-year overview of increasing tramadol utilisation and associated mortality and the impact of tramadol classification in the United Kingdom

9. Author's full name (a separate form must be submitted for each author)

\section{Li-Chia Chen}

10. In checking this box, I confirm I have completed this form to the best of my knowledge. $\bigotimes$

This form is available online by clicking here 


\section{Corresponding author only (Co-authors go to Question 4):}

POTENTIAL STUDY INTERPRETATION CONFLICTS

1. Some or all of the data that were used in this study were provided by a company with a vested interest in the product being studied.

No

2. The sponsor of this project had the right of commenting but the authors retained the right to accept or reject comments or suggestions.

$\mathrm{n} / \mathrm{a}$

3. The sponsor of this project had the right of final editing and/or approval of the manuscript submitted.

$\mathrm{n} / \mathrm{a}$

\section{Corresponding author and Co-authors:}

POTENTIAL FINANCIAL CONFLICTS

4. I, my spouse, or one of my dependent children is an employee of a company whose product is being studied.

No

5. I, my spouse, or one of my dependent children has significant equity interest (>USD 10,000) in the company that owns the product being studied.

No 
6. In the past three years I have:

- been paid as a consultant (or in a similar capacity) by a company with a vested interest in the product being studied, on issues related to the product being studied; No

- been paid as a consultant (or in a similar capacity by a company with a vested interest in the product being studies, on issues unrelated to the product being studied; No

- received research or educational support from a company with a vested interest in the product(s) being studied.

No

7. A company whose product is being studied has provided funding to support the work on this project.

No

If you have answered YES to any of the above questions, or if you have additional personal, commercial or academic conflicts of interest, please draft a statement to publish with the article. e.g., AB has been reimbursed by Safe Drug Ltd. for international conference attendance.

8. Manuscript title (first six words are sufficient)

A fifteen-year overview of increasing tramadol utilisation and associated mortality and the impact of tramadol classification in the United Kingdom

9. Author's full name (a separate form must be submitted for each author)

Roger David Knaggs

10. In checking this box, I confirm I have completed this form to the best of my knowledge. $\square$

This form is available online by clicking here 


\section{Appendices}

\section{Appendix 1. Segmented regression model}

$Y_{t}=\beta_{0}+\beta_{1}{ }^{*}$ time $+\beta_{2}{ }^{*}$ tramadol classification $+\beta_{3}{ }^{*}$ time after tramadol classification

$Y_{t}$ is monthly tramadol utilisation, measured as monthly DDD between October 2010 and September 2015 from NHS digital practice-level dispensing data and CPRD (further stratified by incident and prevalent users).

time refers to time from October 2010 to September 2015 in a monthly base.

Tramadol classification is a binary variable and 1 to denote the time from June 2014.

Time after tramadol classification refers to time from June 2014 to September 2015 in a monthly base.

The baseline trend of monthly tramadol utilisation before classification $(\beta 1)$, the change in the levels of monthly utilisation $(\beta 2)$ and the change in trend of monthly tramadol utilisation after classification $(\beta 3)$ were tested.

Additional time points in the policy development, including the publication of Advisory Council on the Misuse of Drugs recommendation (February 2013), commencing public consultation about tramadol classification (July 2013) and publishing results of the public consultation (March 2014) were included in the segmented regression model for sensitivity analysis. 
Appendix 2. Proportion of the annual tramadol dose prescribed to existing users

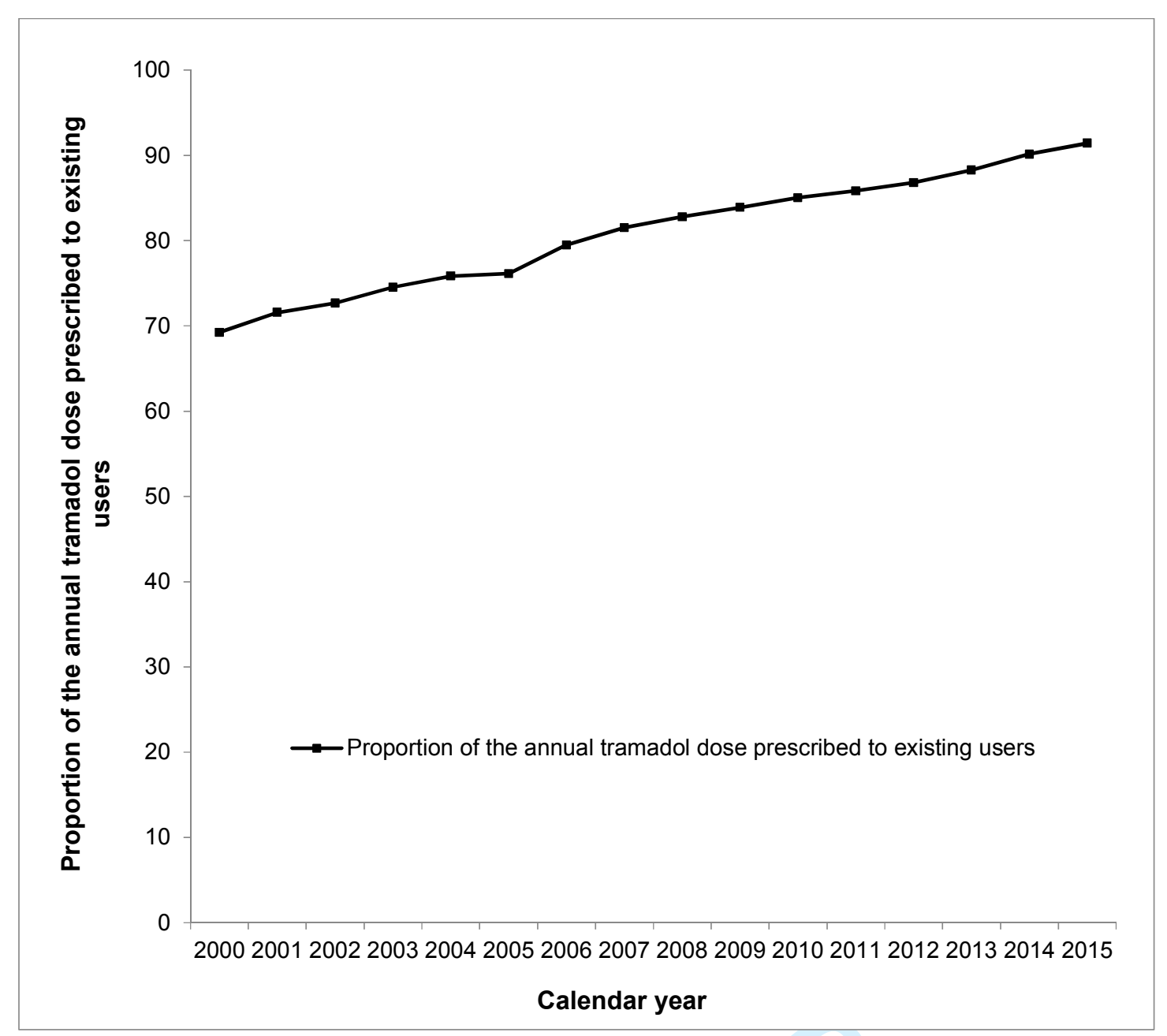

http://mc.manuscriptcentral.com/pds 


\section{Appendix 3. Annual dose and supply days between existing and new tramadol} users

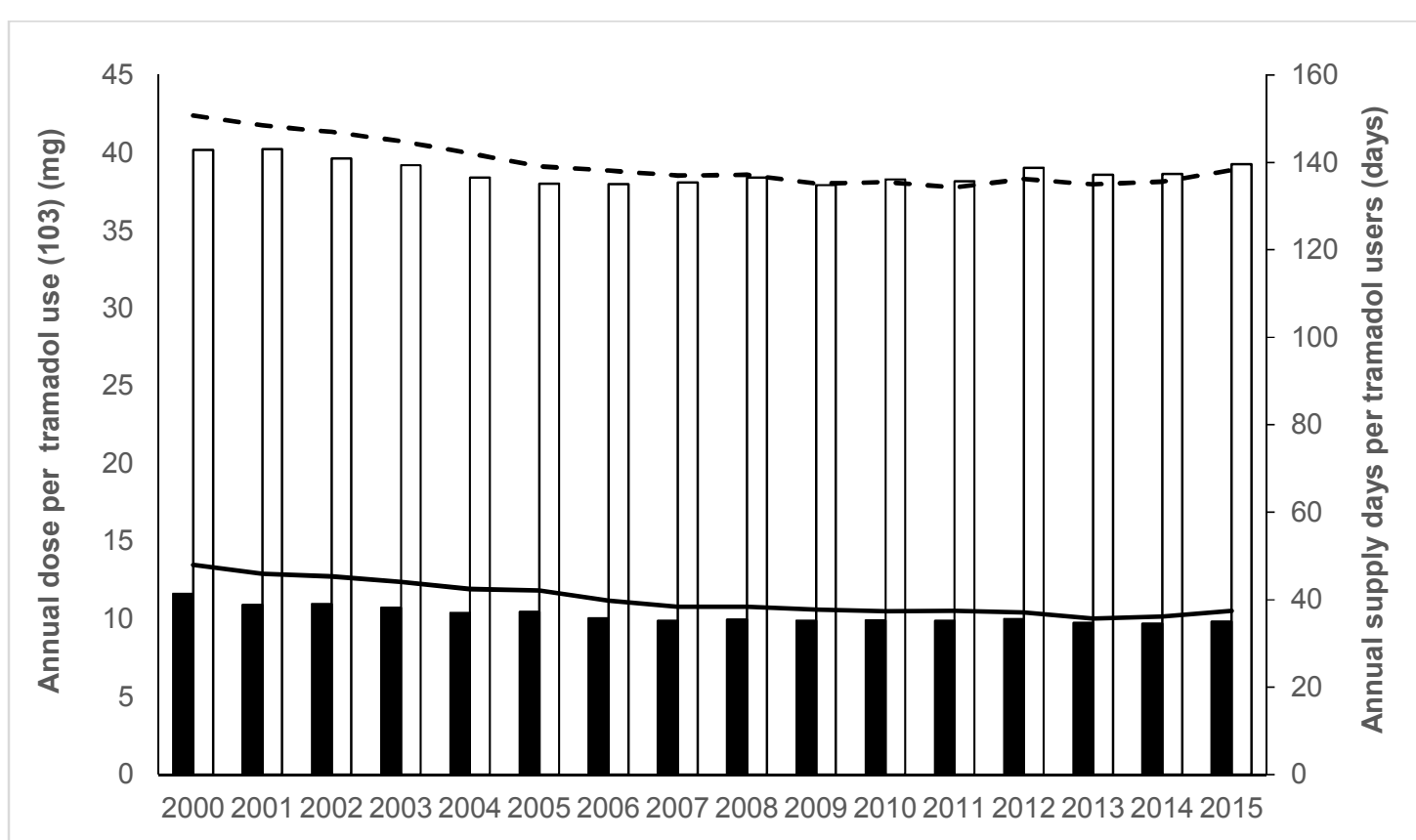

\section{Calendar year}

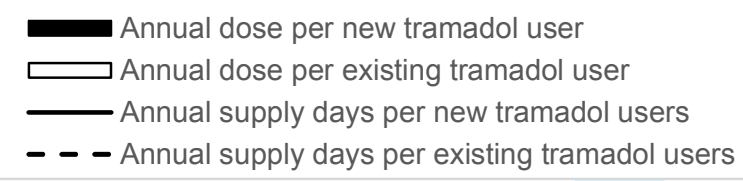

